\title{
Improving Cross Cultural Diversity in the Workplace: A Look at Women and Cultures Globalization, Leadership and Decision Making
}

Ingrid Fray*

St. Johns University, Queens, New York, USA

\begin{abstract}
Almost no American corporation is immune from the impact of globalization. The reality for American corporations is that they must increasingly cope with diverse cross-cultural employees, customers, suppliers, competitors, and creditors. There are 11,553 women and 8,556 males currently enrolled at a major University in New York City. Between fall 2007 and fall 2008 female students accounted for $57 \%$ of the student body while international student population has increased to $40 \%$ vs. $38 \%$. The rate of retention for females has decreased. $61 \%$ of the graduates were females compared to $62 \%$. Internationally female students account for $51 \%$ of the total student and male international students account for $48 \%$ of the student body. International students represent over 100 countries with the top five including, India, China, South Korea, Taiwan, and the Caribbean. Students within these top five countries are studying abroad in the United States on a visa or temporary basis. With the number of international and female students within the university, there are currently no mentorship programs available for these groups. This particular University operates within three campuses in New York City and two in Europe.
\end{abstract}

Keywords: Diversity; Cultures globalization; Leadership; Decision making

\section{Introduction}

Total student population is 20,109 . New student enrollment is up 4,737 to 4,808 while the number of freshman students has also increased. Although the university is culturally diverse the needs of the International students are not being met and it affects the performance in the classroom. Female freshman increase every year however retention rate is low with female students dropping out before their second term. Many times the international students are afraid to speak up in fear of not responding to questions properly or judgment from other students. This stifles the level of success they seek from coming to the United States and not being able to fully grasp or understand the information they seek or are learning. With limited or no support from faculty and/or students, how will international students adjust and gain knowledge as one of the future business leaders of tomorrow? In order for American business leaders to gain understanding of cultural differences, Improving cross cultural diversity in the workplace: a look at women and cultures Dr. Ingrid Fray 3 take advantage of the opportunity of when a young student first enters in the U.S. for educational purposes. Javidan et al. [1] state that to be open minded and to understand the cultures of the different countries, managers need to be able to compare their own cultures with those of other countries. Given the opportunity to learn, share ideas and mentor is an opportunity all universities can take advantage of when students first enter the United States for educational purposes. Findings from the women's college coalition state that mentorship programs create opportunities for encouragement, job placement and a higher retention rate for universities. The two issues to be discussed are cultural differences as Javidan, Dorfman, Sully de Luque and House in state, to be open-minded and to understand the cultures (global connections) of the different countries.

\section{Analysis/China and Women}

The majority of the international students that enter the university are question are from China. Many of these students do not actively participate in class due to the language barrier or do not have a clear understanding of the American culture. Developing a relationship with this particular group helps us study their system and culture which gives us a better understanding how to further reach our goals internationally when working with a Chinese or any other international counterpart. Research has shown, for example the mindsets of East Asians toward business, including the way they define cooperation and competition, are significantly different from those in North America [2]. International and Intranational diversity as described by Tung [2] are managing the interface between expatriates and host country nationals (the former) and Intranational diversity, on the other hand, refers to dealing with the realities of a multiethnic workforce and the increasing participation of women in professional and managerial ranks within a domestic context. We examine the intensity of which we will not only be working with organizations and people from one country, but the influx of immigrants and the momentum in which women are gaining managerial positions within organizations. Graduates of women's colleges constitute Improving cross cultural diversity in the workplace: a look at women and cultures Dr. Ingrid Fray 4 more than $20 \%$ of women in Congress and are $30 \%$ of a Business Week list of rising women stars in corporate America) Women's college coalition Intuitively, globalization is a process fueled by, and resulting in, increasing cross-border flows of goods, services, money, people, information, and culture [3]. Globalization exists on many levels and it is important in cultivating relationships and helping to maintain them. Globalization is an important aspect in also developing relationships cross-culturally with women. The term as Guillen [3] describes also appears linked to cross-border advocacy networks and organizations defending human rights, the environment, women's rights, or world

*Corresponding author: Ingrid Fray, Professor, St. Johns University, Queens, New York United States, Tel: +1 718-990-2000; E-mail: frayi@stjohns.edu

Received September 28, 2017; Accepted October 05, 2017; Published October 13,2017

Citation: Fray I (2017) Improving Cross Cultural Diversity in the Workplace: A Look at Women and Cultures Globalization, Leadership and Decision Making. Arts Social Sci J 8: 301. doi: 10.4172/2151-6200.1000301

Copyright: () 2017 Fray I. This is an open-access article distributed under the terms of the Creative Commons Attribution License, which permits unrestricted use, distribution, and reproduction in any medium, provided the original author and source are credited. 
peace. Foreign direct (excluding portfolio) investment as a percentage of GDP is 2.5 times greater today than twenty years ago-and nearly four times greater in the developing world [3]. Key importing and exporting countries as described by Guillen include China, Taiwan, India, and the Caribbean. Globally each country has their own specialty in various markets. Guillen gives an example of German, French, Japanese, and American firms are competitive in the global economy, but rarely in the same industry and market segment. Each is trying to gain or maintain leadership within their respective countries. House and Aditya examined leadership and studied the success of leaders who led multiple/diverse groups. Both found that $59 \%$ of the variance in leadership emergence was due to leader behavioral flexibility. The ability to get along with others in order to fulfill the goals of the organization is an important aspect of leader and the success of a global marketplace. O'Toole and Galbraith also describe leadership as not an individual responsibility, but shared responsibilities that require two or more individuals to build and sustain a successful organization. As with working within a multicultural organization whether it be domestic or international there is not doubt that teams will be established. Some teams are virtual while others are in office. Virtual team working involves collaboration and teamwork between a geographically and temporally separated work force Nandha Kumar [4]. A manager has to be mindful of the variation in values, attitudes, and behaviors attributable to the multiple forms of culture (cross-national, corporate, professional and industry) and be open to different points of Improving cross cultural diversity in the workplace: a look at women and cultures Dr. Ingrid Fray 5 view. In corporate we are use to just being introduced to individuals and a limited orientation process. Orientation can not replace the use of working with individuals at an early stage of their introduction to business or other study. Tung states traditionally, the ability to manage, work with, or both, people from different racial/ ethnic backgrounds has been required of international managers. To help organizations develop closer relationships with culture we examine the three constructs as developed by Goto [5]. Goto states that the extent to which an individual is familiar with the other individual's culture defines the construct of "knowledge of culture". There are over 200,000 U.S. expatriates worldwide and should be able to identify with cultural differences between their culture and that of the comparison countries (Javidan, et al. [1]. Within that culture of knowledge exists trust issues and the relationships that are built to enable individuals to engage in a success operation to meet its organizational goals. Nandhakumar define trust as 'confidence in the reality of a person or system, regarding a given set of outcomes or events. To understand and develop trust multi-cultural organizations depend on past experience and/or current interaction. Previous experience is often time better because we have at least a past experience whereas to gauge and build a successful relationship. Many teams often depended on an elaborate body of collective knowledge and diverse skills for solving problems; however, they had no history of working together Nandhakumar. The existence of mentorship programs enables individuals to gain guidance and understanding of an organization and its employees. Understanding of culture is imperative for the fulfillment of growth to the current American economy. We are not talking about establishing a women's college but we must examine the importance of these institutions and why they have grown and existed within the past fifty years. As stated by the women's college coalition (2009), the advantages of women's colleges are said to be due in part to:

- The availability of more female mentors and role models among the faculty and top administrators;

- Greater opportunities for and participation in student leadership roles; and Improving cross cultural diversity in the workplace: a look at women and cultures Dr. Ingrid Fray 6,

- Higher percentages of students enrolled in the traditionally-male disciplines of math, science, and engineering.

By establishing conditions that foster student faculty interactions, women's colleges appear to have provided important support for women in fields where they are underrepresented. These skills, which are typically associated with career success and leadership, reveal some of conditions that contribute to the high production of leaders from women's colleges women's college coalition [6]. In the area of gender differences, research has shown that there can be significant differences in communication patterns and styles of leadership between males and females. Interestingly enough many organizations are requiring their staff to undertake temporary overseas assignments as part of their international mentorship program A growing number of companies consider them as part of overall career development for those people with potential for advancement to senior management positions Tung. As part of the new mentorship process, Tung lists the multiple purposes that an overseas assignment serves:

- Development of a global orientation. An international assignment can sensitize the executive to the limitations of an ethnocentric approach. The person will be exposed to different mindsets, ways of conducting business, and doing things in general.

- Provision of greater opportunities for the expatriate to assume broader responsibilities. Because the overseas operation is usually smaller in size than corporate headquarters, the international executive is required to undertake a broader range of activities with their commensurate responsibilities and authority. Closely associated with this is greater exposure to a more diverse range of disciplines and industries. As we further examine collaboration between groups with a multicultural level we notice a vast difference in how effective collaboration can become. Also, given the competitive challenges of organizational growth, globalization, and expansion through strategic alliances, the ability to effectively develop and maintain strategic partnerships and alliances among competitors and multicultural/ multilingual relations has become a critical competence Improving cross cultural diversity in the workplace: a look at women and cultures. Lewicki, et al. [7] given the opportunity we have at This university the indication is the ability to network with these groups prior to them moving back to their native country. An understanding of workgroups and relationships enables the researcher to examine how cultures are defined, what defines them and how we can take advantage of the opportunity that we have in the early relationship.

\section{Conclusion}

Women look for encouragement and engage in positive reinforcement from other women. They tend to be more comfortable from taking advice and gaining new ideas from the mentorship of other women. Through the development of mentorship programs and schools specifically geared towards women this enables the ability for this group to perform and achieve perceived goals by their respective organizations. According to the 1995 Federal Glass Ceiling Commission report, Good for Business: Making Full Use of the Nation's Human Capital, African Americans account for $12.1 \%$ of the population in the United States, and women constitute one half of the productive workforce.

Through our collective data and findings Tung has identified three key elements in establishing better relationships with women: 
- The introduction of an awareness training program, titled "Women and Men as Colleagues," to address "how traditional and often-unconscious attitudes distort the selection, development, and promotion of "women".

- The institution of corporate and community sponsorship programs to support the education and career development of women employees.

- The establishment of flexible work arrangements (flextime, flexible work week, permanent part time, job sharing, and flex place) to accommodate employees with multiple commitments. Women colleges have developed a place for sharing and active learning. With the establishment of women colleges, programs within co-ed universities have also looked to Improving cross cultural diversity in the workplace: a look at women and cultures Dr. Ingrid Fray 8 examine and possible replicate the success of such programs to future female business leaders. Why with the success of women business leaders are they still neglected in certain business areas? How will a mentorship program for women at This university change the perception of business leaders, or will it? What is the university looking for if they were to launch this program? Is it financial, the study of women to better understand placing them in organizations, or that these future leaders will be at one point entrepreneurs and will it benefit the graduates at the university? Within our diverse cultural groups we will be asked to work on assigned tasks or assigned to temporary groups. Within these temporary systems a formation of trust needs to be developed to enable groups to coincide and achieve a desired outcome from both parties. Within these temporary systems we examined what a group needs in order to be successful. Meyerson et al. [8] described the formation of trust by organization, especially diverse and their success be based on a better history of working together, understand of each task and that of the individuals assigned to that task and continuous communication. We cannot escape the fact that organizations will become more diverse and have no choice but to adapt to our changing society. Prior to working within a multi-cultural society how should we prepare? Should the United States adapt to a changing society or should a changing society adapt to us? Through the research we can gather that many organizations recognize the need to develop a young relationship with international workers and students. At the beginning of a young relationship we can discuss common differences in an open manner which will later benefit either parties while they are here temporarily (or temporary system) at the University or any other work related places. Meyerson, et al. [8] examine temporary systems and state, one way to resolve this puzzle is to look more closely at the properties of trust and of temporary systems. A closer look suggests that temporary groups and organizations are tied together by trust, but it is a form of trust that some unusual properties [8]. A second implication of analysis is that if people find it hard to resolve uncertainty quickly with a move Improving cross cultural diversity in the workplace: a look at women and cultures Dr. Ingrid Fray toward either unwarranted trust or unwarranted distrust, then we would expect to see more idiosyncratic resolutions of trust uncertainty consistent with personality predispositions and prior implicit theories of trust $[9,10]$.

\section{Future Research}

As the United States becomes more globally accessible their needs to be a plan of orientation and education for expatriates. What can we expect from these findings but to understand that we have limited understanding of cultures and how they make decisions? If other nations are surpassing or have caught up to the United States in development then how can we use our ability to meet them in the infancy of their development? Individuals who assume position of power must also know what is expected or what others expect of them. In a power situation there must be clear communication between the person who initiates policy and the person who must comply (Bachrach and Baratz [9]). How can the United States and other cultures communicate each other's views and opinions on issues that even though they disagree on, there can at least be a better understanding and compromise?

\section{References}

1. Javidan M, Dorfman PW, Sully de Luque M, House RJ (2006) In the eye of the beholder: Cross cultural lessons in leadership from project GLOBE. Academy of Management Perspectives 23: 409-473.

2. Tung R (1997) Cross cultural work groups. The Claremont Symposium on Applied Social Psychology.

3. Guillen $M(2001)$ Is globalization civilizing, destructive or feeble? A critique of five key debates in the social science. Literature Annual Review of Sociology pp: 235-260.

4. Nandhakumar J (1999) Virtual teams and lost proximity: consequences on trus relationships. In: Jackson P (ed.) Virtual Working NY: Routledge, pp: 46-56.

5. Goto SG (1997) Majority and minority perspectives on cross cultural interactions.

6. http://www.womenscolleges.org.

7. Lewicki R, McAllister D, Bies R (1998) Trust and distrust: new relationships and realties. Academy of Management Review 23: 43-460.

8. Meyerson D, Weick K, Kramer R (1996) Swift trust and temporary groups In: Kramer R, Tyler TR (eds.) Trust in organizations: Frontiers of theory and research. Thousand Oaks, Calif.: Sage, pp: 166-195

9. Bachrach P, Baratz M (1963) Decisions and non-decisions: an analytica framework. American Political Science Review 57: 632-642.

10. Weick K, Quinn R (1999) Organizational change and development. Annual Review of Improving cross cultural diversity in the workplace: a look at women and cultures, 50: 361-386. 